\title{
PENGETAHUAN DAN SIKAP KELUARGA DALAM PELAKSANAAN PERILAKU HIDUP BERSIH DAN SEHAT DI WILAYAH KERJA PUSKESMAS SOMBAOPU GOWA
}

\author{
Knowledge and Family Attitude in the Implementation of Clean and Healthy Behavior in \\ the Areas of Puskesmas Sombaopu Gowa
}

Sukma Saini, Sitti Aminah

Diploma III Keperawatan, Jurusan Keperawatan Poltekkes Kemenkes Makassar email: ogi.badisca@gmail.com

HP: 085242663061

\begin{abstract}
PHBS is a reflection of the pattern of family life that always pay attention and maintain the health of all family members. One of the main programs to achieve healthy behavior for all residents of Indonesia is Health promotion program. The purpose of this study is to determine the relationship between the level of knowledge and attitudes of the family with the implementation of PHBS in area of the Puskesmas Sombaopu Gowa. The type of this study was observational by using Cross Sectional design / design design. In the data analysis the result of the statistical test used is chi square test $\left(X^{2}\right)$. The result of the research shows that there is a correlation between knowledge with the implementation of PHBS in the area of Puskesmas Sombaopu Gowa ( -value $=0.000<\alpha=0.05$ ) attitude with the implementation of PHBS in the area of Puskesmas Sombaopu Gowa ( $p$-value $=0.000<\alpha=$ 0.05). Suggestions related to the findings of this research is expected to be more intensive and actively involved in the cooperation of periodic counseling about the importance and the benefits of PHBS so as to provide motivation for families in the application of PHBS on the order of the house in a broader scope so as to achieve the desired results.
\end{abstract}

Keywords: Knowledge, PHBS and Attitude

\begin{abstract}
ABSTRAK
PHBS merupakan cerminan pola hidup keluarga yang senantiasa memperhatikan dan menjaga kesehatan seluruh anggota keluarga. Salah satu program utama untuk mencapai perilaku sehat bagi semua penduduk Indonesia adalah program promosi Kesehatan.Tujuan penelitian ini adalah untuk mengetahui hubungan antara tingkat pengetahuan dan sikap keluarga dengan pelaksanaan PHBS di wilayah kerja Puskesmas Sombaopu Kabupaten Gowa. Jenis penelitian ini adalah observasioal dengan menggunakan desain/rancangan penelitian Cross Sectional. Dalam analisis data hasil penelitian uji statistik yang digunakan adalah uji chi square ( $\mathrm{X}^{2}$ ). Hasil penelitian menunjukkan ada hubungan pengetahuan dengan pelaksanaan PHBS di wilayah kerja Puskesmas Sombaopu Kabupaten Gowa ( $p$ value $=0,000<\alpha=0,05)$ dan ada hubungan sikap dengan pelaksanaan PHBS di wilayah kerja Puskesmas Sombaopu Kabupaten Gowa ( $p$-value $=0,000<\alpha=0,05)$.Saran terkait
\end{abstract}


dengan temuan hasil penelitian ini yaitu diharapkan pihak yang terkait lebih intensif dan terlibat aktif dalam kerjasama mengadakan penyuluhan berkala tentang pentingnya dan manfaat dari PHBS sehingga memberikan motivasi bagi keluarga dalam penerapan PHBS pada tatanan rumah dalam lingkup yang lebih luas sehingga dapat mencapai hasil sesuai yang diharapkan.

Kata kunci : Pengetahuan, PHBS dan Sikap

\section{PENDAHULUAN}

Sehat menurut WHO adalah suatu keadaan yang sempurna baik secara fisik, mental dan sosial serta tidak hanya bebas dari penyakit atau kelemahan. Sehat menurut UU nomor 23 tahun 1992 tentang kesehatan menyatakan bahwa kesehatan adalah keadaan sejahtera dari badan, jiwa dan sosial yang memungkinkan hidup produktif secara sosial dan ekonomi.

Kondisi sehat dapat dicapai dengan mengubah perilaku dari yang tidak sehat menjadi perilaku sehat dan menciptakan lingkungan sehat di rumah tangga. Rumah tangga berperilaku hidup bersih dan sehat dapat terwujud apabila ada keinginan, kemauan dan kemampuan para pengambil keputusan dan lintas sektor terkait agar PHBS menjadi program prioritas dan menjadi salah satu agenda pembangunan di Kabupaten / Kota, serta didukung oleh masyarakat (Atikah, 2012). Perilaku, khususnya Perilaku Hidup Bersih dan Sehat (PHBS) merupakan komponen penting dalam pembangunan kesehatan dimana diperlukan adanya kesadaran, kemampuan, dan kemauan hidup sehat dari setiap penduduk sehingga derajat kesehatan yang optimal dapat terwujud dan dengan demikian masyarakat diharapkan mampu berpartisipasi dalam memelihara dan meningkatkan derajat kesehatannya sendiri. Sedangkan pembangunan kesehatan mempunyai peran dalam menentukan peningkatan kualitas Sumber Daya Manusia (SDM) yang merupakan fokus pembangunan nasional. Oleh karena itu, PHBS ini perlu diselenggarakan sebaik-baiknya agar dapat memberikan sumbangan yang nyata baik dalam pembangunan kesehatan maupun pembangunan nasional.

Perilaku Hidup Bersih dan Sehat (PHBS) adalah bentuk perwujudan Paradigma Sehat dalam budaya hidup perorangan, keluarga, dan masyarakat yang berorientasi sehat, bertujuan untuk meningkatkan, memelihara, dan melindungi kesehatannya baik fisik, mental spiritual, maupun sosial. Selain itu, PHBS ini dapat dijadikan indikator dari derajat kesehatan suatu daerah tertentu. Bila PHBS di suatu daerah cukup baik maka dengan sendirinya akan memperkecil masalah-masalah kesehatan, 
juga memperkecil kemungkinan terjadinya suatu wabah penyakit. Dengan kata lain, PHBS ini merupakan salah satu bentuk tindakan preventif dalam bidang kesehatan.

Keluarga mempunyai peran penting dalam meningkatkan kualitas kesehatan masyarakat, karena dalam keluarga terjadi komunikasi dan interaksi antara anggota keluarga yang menjadi awal penting dari suatu proses pendidikan perilaku. Pelaksanaan perilaku hidup bersih dan sehat sejak dini dalam keluarga dapat menciptakan keluarga yang sehat dan aktif dalam setiap upaya kesehatan dimasyarakat.

PHBS adalah semua perilaku yang dilakukan atas kesadaran sehingga anggota keluarga atau keluarga dapat menolong dirinya sendiri di bidang kesehatan dan berperan aktif dalam kegiatan-kegiatan kesehatan dimasyarakat dan PHBS di rumah tangga adalah upaya untuk memberdayakan anggota rumah tangga agar tahu, mau, dan mampu mempraktekkan perilaku hidup bersih dan sehat serta berperan aktif dalam gerakan kesehatan di masyarakat.

Hasil Riskesdas (Riset Kesehatan Dasar) 2007 mengumpulkan 10 indikator tunggal Perilaku Hidup Bersih dan Sehat (PHBS) yang terdiri dari enam indikator individu dan empat indikator rumah tangga (Sumber : Dinkes Kabupaten/Kota Tahun 2012).

Dari hasil Riskesdas 2007 juga didapatkan data bahwa tercatat penduduk yang telah memenuhi kriteria PHBS baik sebesar 44\%, lebih tinggi dari angka nasional $(38,7 \%)$. Terdapat sepuluh kabupaten dengan persentase PHBS di bawah angka provinsi (Sumber : Riskesdas Tahun 2007).

Berdasarkan data persentase penduduk ber PHBS per kabupaten/kota di Sulawesi Selatan tahun 2013, di Kabupaten Gowa dari total 163.277 rumah tangga, terdapat $36.385(22,28 \%)$ rumah tangga yang dipantau dan dari jumlah tersebut hanya $9.202(25,29 \%)$ rumah tangga yang berPHBS (Profil Kesehatan Sulawesi Selatan, 2014).

Berdasarkan data awal yang dikumpulkan tercatat jumlah penduduk Kecamatan Sombaopu sebanyak 151.916 jiwa yang terdiri dari laki-laki 75.577 jiwa dan perempuan 76.339 jiwa dengan jumlah rumah tangga 31.512, sedangkan luas wilayah $28,09 \mathrm{Km}^{2}$ serta kepadatan penduduk 5.408 jiwa per $\mathrm{Km}^{2}$ yang menunjukkan bahwa Kecamatan Sombaopu adalah kecamatan terpadat dari seluruh kecamatan di Kabupaten Gowa (Badan Pusat Statistik Kabupaten Gowa, 2015). 
Hal ini bisa menjadi faktor predisposisi munculnya berbagai macam masalah kesehatan bilamana jumlah penduduk dan kepala keluarga yang besar tidak memahami dan menerapkan pola dan perilaku hidup bersih dan sehat khususnya dalam tatanan rumah tangga..

Dengan demikian maka peneliti tertarik untuk melakukan penelitian "Hubungan antara tingkat pengetahuan dan sikap keluarga dengan pelaksanaan PHBS di Wilayah Kerja Puskesmas Sombaopu Kabupaten Gowa”.

\section{METODE}

Jenis penelitian adalah observasioal dengan menggunakan desain/rancangan penelitian cross Sectional Study

\section{Lokasi dan Waktu Penelitian}

1. Lokasi

Lokasi penelitian di wilayah kerja Puskesmas Sombaopu Kabupaten Gowa.

2. Waktu

Penelitian ini dilaksanakan selama 4 bulan yaitu mulai bulan Juni sampai dengan September 2016.

\section{Populasi}

Populasi dalam penelitian ini adalah keluarga yang berkunjung ke puskesmas Sombaopu periode bulan Januari sampai dengan bulan Mei 2016 yaitu sebesar 60 orang.

\section{Sampel}

Sampel dalam penelitian ini adalah anggota populasi yang diambil secara simple random sampling dengan jumlah sampel pada penelitian ini adalah 24 responden.

\section{HASIL}

Pengumpulan data penelitian dilakukan mulai bulan Agustus sampai dengan Oktober 2016 di Wilayah Kerja Puskesmas Somba Opu Kabupaten Gowa. Penelitian dilakukan pada 24 responden baik yang datang ke Puskesmas maupun yang hadir pada saat pelaksanaan Posyandu.. Responden terlebih dahulu dijelaskan tentang maksud dan tujuan penelitian sehingga responden dapat memutuskan untuk ikut atau tidak dalam penelitian yang dilaksanakan. Bila responden bersedia maka responden menandatangani format informed consent penelitian yang telah disediakan.

Dari hasil pengolahan data yang dilakukan disajikan dalam bentuk distribusi frekuensi meliputi karakteristik responden dan analisis dengan uji ChiSquare test. 
1. Data Karakteristik Responden

Tabel 1

Distribusi responden berdasarkan umur

\begin{tabular}{lccc}
\hline No & Umur & F & $(\%)$ \\
\hline 1. & $20-30$ thn & 6 & 25 \\
2. & $31-40$ thn & 9 & 37,5 \\
3. & $41-50$ thn & 3 & 12,5 \\
4. & $51-60$ thn & 3 & 12,5 \\
5. & $>60$ thn & 3 & 12,5 \\
\hline & Jumlah & 24 & 100
\end{tabular}

(Data Primer, Agustus 2016).

Berdasarkan tabel 1 jumlah responden terbanyak dari 24 responden adalah reponden dengan rentang umur 31 - 40 tahun dengan jumlah distribusi sebanyak 9 responden $(47,5 \%)$, dan terendah adalah reponden dengan rentang umur41- > 60 tahun yang berjumlah 2 responden $(8,3 \%)$.

Tabel 2

Distribusi responden berdasarkan jenis kelamin

\begin{tabular}{llcc}
\hline No & $\begin{array}{c}\text { Jenis } \\
\text { Kelamin }\end{array}$ & Frekuensi & $\begin{array}{c}\text { Persentase } \\
(\%)\end{array}$ \\
\hline 1. & Laki-laki & 0 & 0 \\
2. & Perempuan & 24 & 100 \\
\hline & Jumlah & 24 & 100
\end{tabular}

(Data Primer, Agustus 2016).

Berdasarkan tabel 2 dapat diketahui

bahwa keseluruhan responden adalah berjenis kelamin perempuan yaitu 24 orang $(100 \%)$.
Tabel 3

Distribusi responden berdasarkan pendidikan terakhir

\begin{tabular}{llcc}
\hline No & Pendidikan & Frekuensi & $\begin{array}{c}\text { Persentase } \\
(\%)\end{array}$ \\
\hline 1. & SD & 2 & 8,3 \\
2. & SMP & 2 & 8,3 \\
3. & SMA & 12 & 50 \\
4.. & D3/S1 & 8 & 33,3 \\
& & & \\
\hline & Jumlah & 24 & $100 \%$ \\
\hline
\end{tabular}

(Data Primer, Agustus 2016).

Berdasarkan tabel 3 dapat diketahui bahwa responden dengan pendidikan SMA merupakan responden dengan jumlah terbanyak dari 24 responden yaitu 12 responden (50\%) sedangkan SD dan SMP merupakan responden dengan distribusi terendah yang jumlahnya masing-masing 2 responden $(8,3 \%)$.

Tabel 4

Distribusi responden berdasarkan pekerjaan

\begin{tabular}{llcc}
\hline $\mathrm{N}$ & Pekerjaan & $\begin{array}{c}\text { Frekuens } \\
\mathrm{i}\end{array}$ & $\begin{array}{c}\text { Persentase } \\
(\%)\end{array}$ \\
\hline 1. & IRT & 15 & 62.5 \\
2. & PNS & 3 & 12,5 \\
3. & Wiraswast & 1 & 4,2 \\
4. & a & 5 & 20,8 \\
& Lain-lain & & \\
\hline & Jumlah & 24 & 100
\end{tabular}

(Data Primer, Agustus 2016).

Berdasarkan tabel 4 dapat diketahui bahwa responden dengan jenis pekerjaan Ibu rumah tangga (IRT) merupakan responden dengan jumlah terbanyak yaitu 15 responden (62,5\%) sedangkan wiraswasta merupakan responden dengan 
distribusi terendah yang jumlahnya 1 responden $(4,2 \%)$.

\section{Data Khusus}

Data khusus responden mencakup pengetahuan, sikap dan terapan PHBS yang dapat dilihat dalam tabel di bawah ini :

a. Pengetahuan

Tabel 5

Kategori pengetahuan responden

\begin{tabular}{llcc}
\hline $\begin{array}{c}\mathrm{N} \\
\mathrm{o}\end{array}$ & $\begin{array}{c}\text { Pengetahu } \\
\text { an }\end{array}$ & $\begin{array}{c}\text { Frekuen } \\
\text { si }\end{array}$ & $\begin{array}{c}\text { Persenta } \\
\text { se }(\%)\end{array}$ \\
\hline 1. & Baik & 17 & 70.8 \\
2. & Cukup & 7 & 29.2 \\
\hline & Jumlah & 24 & 100
\end{tabular}

(Data Primer, Agustus 2016).

Berdasarkan tabel 5 kategori pengetahuan dari 24 responden didapatkan hasil, sebagian besar responden memiliki pengetahuan baik yaitu 17 responden $(70,8 \%)$ dan hanya 7 responden $(29,2 \%)$ memiliki pengetahuan yang cukup.

b. Sikap

Tabel 6

Kategori sikap responden

\begin{tabular}{llcc}
\hline No & Sikap & Frekuensi & $\begin{array}{c}\text { Persentase } \\
(\%)\end{array}$ \\
\hline 1. & Baik & 18 & 75 \\
2. & Kurang & 6 & 25 \\
\hline & Jumlah & 24 & 100
\end{tabular}

(Data Primer, Agustus 2016).

Tabel 6 menunjukkan bahwa dari 24 responden, sebagian besar atau 18 responden $(75 \%)$ diantaranya memiliki sikap baik dan 6 responden $(25 \%)$

lainnya dengan sikap kurang baik

\section{c. Pelaksanaan PHBS}

Tabel 7

Kategori Pelaksanaan PHBS

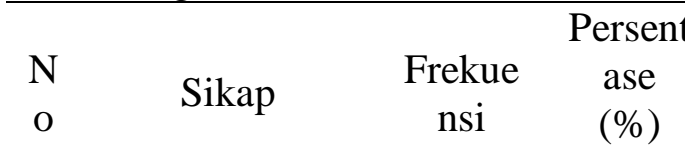

1. Melaksanakan $17 \quad 70,8$

2. Tidak 729,2 melaksanakan Jumlah $\quad 24 \quad 100 \%$

(Data Primer, Agustus 2016).

Tabel 7 menunjukkan bahwa dari 24 responden, sebagian besar atau 17 responden $(70,8 \%)$ diantaranya melaksanakan PHBS dan terdapat 7 responden $(29,2 \%)$ lainnya tidak melaksanakan PHBS.

3. Analisis Bivariat

Tabel 8

Hubungan pengetahuan dengan pelaksanaan PHBS di Wilayah Kerja Puskesmas Sombaopu Kabupaten Gowa

\begin{tabular}{|c|c|c|c|c|c|c|}
\hline \multirow[b]{2}{*}{$\begin{array}{l}\text { Penget } \\
\text { ahuan }\end{array}$} & \multicolumn{4}{|c|}{ Pelaksanaan PHBS } & \multirow[b]{2}{*}{$\begin{array}{l}\text { To } \\
\text { tal }\end{array}$} & \multirow[b]{2}{*}{$\begin{array}{c}\mathrm{p} \\
- \\
\mathrm{va} \\
\mathrm{lu} \\
\mathrm{e}\end{array}$} \\
\hline & $\begin{array}{l}\text { mela } \\
\text { ksan } \\
\text { akan }\end{array}$ & $\%$ & $\begin{array}{c}\text { Tida } \\
\mathrm{k} \\
\text { mel } \\
\text { aksa } \\
\text { nak } \\
\text { an } \\
\end{array}$ & $\%$ & & \\
\hline Baik & 16 & $\begin{array}{c}66, \\
7\end{array}$ & 1 & 4,2 & 17 & $\begin{array}{c}0, \\
00 \\
0\end{array}$ \\
\hline Cukup & 1 & 4,2 & 6 & 25 & 7 & \\
\hline Total & 27 & $\begin{array}{c}70, \\
8\end{array}$ & 65 & $\begin{array}{c}29, \\
2\end{array}$ & 24 & \\
\hline
\end{tabular}

Dari tabel 5.8 diatas didapatkan bahwa 
hasil penelitian menunjukkan hubungan pengetahuan dengan pelaksanaan PHBS di Wilayah Kerja Puskesmas Sombaopu Kabupaten Gowa, terdapat lebih dari separuh responden yaitu 16 responden $(66,7 \%)$ yang memiliki pengetahuan yang baik dan melaksanakan PHBS, dan hanya 1 responden $(4,2 \%)$ yang memiliki pengetahuan yang cukup dan melaksanakan PHBS.

Berdasarkan uji Chi-Square didapatkan $p$-value $=0,000$ maka secara statistik ada hubungan yang bermakna antara pengetahuan pelaksanaan PHBS di Wilayah Kerja Puskesmas Sombaopu Kabupaten Gowa, yaitu semakin baik pengetahuan yang dimiliki keluarga maka akan semakin baik pula pelaksanaan/penerapan PHBS di tatanan rumah tangga di Wilayah Kerja Puskesmas Sombaopu Kabupaten Gowa, dan sebaliknya semakin rendah pengetahuan keluarga maka akan semakin tidak melaksanakan / menerapkan PHBS di tatanan rumah tangga di Wilayah Kerja Puskesmas Sombaopu Kabupaten Gowa.
Tabel 5.9

Hubungan sikap dengan pelaksanaan PHBS di Wilayah Kerja Puskesmas Sombaopu Kabupaten Gowa.

\begin{tabular}{|c|c|c|c|c|c|c|}
\hline \multirow[b]{2}{*}{$\begin{array}{c}\text { Sika } \\
\text { p }\end{array}$} & \multicolumn{4}{|c|}{ Pelaksanaan PHBS } & \multirow[b]{2}{*}{$\begin{array}{c}\text { Tot } \\
\text { al }\end{array}$} & \multirow[b]{2}{*}{$\begin{array}{l}\mathrm{p}- \\
\text { val } \\
\text { ue }\end{array}$} \\
\hline & $\begin{array}{l}\text { mel } \\
\text { aks } \\
\text { ana } \\
\text { kan }\end{array}$ & $\%$ & $\begin{array}{c}\text { Tida } \\
\mathrm{k} \\
\text { mela } \\
\text { ksan } \\
\text { akan }\end{array}$ & $\%$ & & \\
\hline Baik & 17 & $\begin{array}{l}70 \\
, 8\end{array}$ & 1 & $\begin{array}{l}4, \\
2\end{array}$ & 18 & \multirow{3}{*}{$\begin{array}{c}0,0 \\
00\end{array}$} \\
\hline $\begin{array}{c}\text { Kura } \\
\text { ng }\end{array}$ & 0 & 0 & 6 & 25 & 6 & \\
\hline $\begin{array}{c}\text { Tota } \\
1\end{array}$ & 17 & $\begin{array}{l}70 \\
, 8\end{array}$ & 7 & $\begin{array}{r}29 \\
, 2\end{array}$ & 24 & \\
\hline
\end{tabular}

Dari tabel 5.9 diatas didapatkan bahwa hasil penelitian menunjukkan hubungan sikap dengan pelaksanaan PHBS di Wilayah Kerja Puskesmas Sombaopu Kabupaten Gowa, terdapat lebih dari separuh responden yaitu 17 responden $(70,8 \%)$ yang memiliki sikap yang baik dan melaksanakan PHBS, dan tidak satupun responden (0\%) yang memiliki pengetahuan yang kurang dan melaksanakan PHBS.

Berdasarkan uji Chi-Square didapatkan $\mathrm{p}$-value $=0,000$ maka secara statistik ada hubungan yang bermakna antara sikap dengan pelaksanaan PHBS di Wilayah Kerja Puskesmas Sombaopu Kabupaten Gowa, yaitu semakin baik sikap yang dimiliki keluarga maka akan 
semakin

baik

pula

pelaksanaan/penerapan PHBS di tatanan

rumah tangga di Wilayah Kerja

Puskesmas Sombaopu Kabupaten Gowa, dan sebaliknya semakin kurang baik sikap keluarga maka akan semakin tidak melaksanakan / menerapkan PHBS di tatanan rumah tangga di Wilayah Kerja Puskesmas Sombaopu Kabupaten Gowa.

\section{PEMBAHASAN}

1. Hubungan pengetahuan dengan pelaksanaan PHBS di Wilayah Kerja Puskesmas Sombaopu Kabupaten Gowa.

Berdasarkan hasil penelitian diketahui bahwa kategori pengetahuan dari 24 responden sebagian besar berada pada kategori pengetahuan baik yaitu 17 responden $(70,8 \%)$ dan hanya 7 responden $(29,2 \%)$ memiliki pengetahuan yang cukup.

Selanjutnya berdasarkan uji ChiSquare didapatkan p-value $=0,000$ maka secara statistik ada hubungan yang bermakna antara pengetahuan dengan dengan pelaksanaan PHBS di Wilayah Kerja Puskesmas Sombaopu Kabupaten Gowa.

Hal ini menunjukan bahwa sebagian besar responden mempunyai pengetahuan baik dan mengerti tentang pentingnya pola perilaku hidup bersih dan sehat (PHBS) sehingga berimplikasi pada penerapan/pelaksanaan PHBS yang baik pula.

Sebagian besar responden mengetahui dan menyadari bahwa perilaku hidup bersih dan sehat khususnya dalam penyediaan air bersih dan konsumsi air minum yang sehat, perilaku mencuci tangan yang benar serta penggunaan jamban sesuai syarat kesehatan akan menghindarkan anggota keluarga dari resiko terjadinya penyakit terutama yang ditimbulkan dari perilaku yang terkait dengan kebiasaan-kebiasaan tersebut.

Meskipun demikian, masih terdapat 7 responden $(29,2 \%)$ memiliki pengetahuan yang cukup dan penerapan PHBS dalam tatanan rumah tangga yang kurang pula. Kurangnya pengetahuan responden ini dapat disebabkan beberapa faktor antara lain masih rendahnya tingkat pendidikan responden yang mana terlihat bahwa penyebaran responden berdasarkan tingkat pendidikan masih berada pada kelompok tingkat pendidikan menengah ke bawah.. Responden dengan pendidikan SD sampai dengan SMA masih mendominasi dengan jumlah 16 orang $(66,6 \%)$ sedangkan 
responden dengan latar belakang pendidikan Diploma/S1 hanya berjumlah 8 orang $(33,4 \%)$.

Hal tersebut sesuai dengan apa yang diungkapkan oleh Notoatmodjo (2010) yang menyatakan bahwa pengetahuan dipengaruhi oleh beberapa faktor, salah satunya adalah tingkat pendidikan yang mana secara umum, orang yang berpendidikan lebih tinggi akan memiliki pengetahuan yang lebih luas daripada orang yang berpendidikan lebih rendah dan dengan pendidikan dapat menambah wawasan atau pengetahuan seseorang

Pengetahuan pada dasarnya adalah pemahaman tentang hal ikhwal kehidupan yang diperoleh dari pendidikan formal atau informal. Pengetahuan adalah merupakan hasil "tahu", dan ini terjadi setelah orang melakukan pengindraan terjadi melalui panca indra manusia, yakni: indra penglihatan, pendengaran, penciuman, rasa, dan raba. Sebagian besar pengetahuan manusia diperoleh melalui mata dan telinga, Notoatmodjo (2010).

Hal tersebut didukung pula oleh pendapat Lawrence Green dalam Notoatmodjo (2010) yang menyatakan bahwa peningkatan pengetahuan mempunyai hubungan yang positif dengan perubahan variabel perilaku. Pengetahuan dapat diperoleh dari tingkat pendidikan seseorang sehingga menyebabkan realitas cara berfikir dan ruang lingkup jangkauan berfikirnya semakin luas.

2. Hubungan sikap dengan pelaksanaan PHBS di Wilayah Kerja Puskesmas Sombaopu Kabupaten Gowa

Berdasarkan hasil penelitian mengenai sikap responden didapatkan bahwa dari 24 responden, sebagian besar atau 18 responden (75\%) diantaranya memiliki sikap baik dan 6 responden (25\%) lainnya dengan sikap kurang baik.

Selanjutnya dari hasil tabulasi silang antara sikap dan terapan PHBS didapatkan hasil berupa lebih dari separuh responden yaitu 17 responden $(70,8 \%)$ yang memiliki sikap yang baik dan melaksanakan PHBS, dan tidak satupun responden (0\%) yang memiliki pengetahuan yang kurang.

Hasil uji Chi-Square didapatkan pvalue $=0,000$ maka secara statistik ada hubungan yang bermakna antara sikap dengan pelaksanaan PHBS di Wilayah Kerja Puskesmas Sombaopu Kabupaten Gowa.

Meskipun secara umum hasil penelitian menunjukkan adanya hubungan yang bermakna secara statistik, akan tetapi pada kenyataannya masih terdapat 1 
reponden $(4,2 \%)$ dari 24 responden yang memiliki sikap baik namun tidak melaksanakan atau dengan kata lain responden tersebut memiliki sikap yang positif akan tetapi dalam penerapan PHBS dalam tatanan rumah tangganya masih dalam kategori kurang baik.

Sikap negatif klien tersebut disebabkan karena responden belum memahami sepenuhnya tentang beberapa perilaku hidup bersih dan sehat dalam kehidupan sehari-hari khususnya dalam tatanan rumah tangga. Sehingga pengejewantahan lewat perilaku pun tidak maksimal. Padahal aspek pengetahuan secara menyeluruh sangat lah penting peranannya dalam membentuk sikap positif terlebih lagi dalam perwujudannya dalam bentuk perilaku sehari-hari.

Terbentuknya sikap yang positif kaitannya dengan penerapan perilaku hidup bersih dan sehat (PHBS) juga dipengaruhi oleh pengetahuan yang dimiliki oleh individu tersebut. Pengetahuan merupakan dasar yang penting untuk terbentuknya tindakan seseorang, pengetahuan itu sendiri penting untuk mendukung psikis dan perilaku setiap hari sehingga pengetahuan merupakan faktor yang mendukung tindakan seseorang (Notoatmodjo, 2010)

Seseorang berpengetahuan cukup tentang suatu objek maka akan terbentuk pula sikap positif terhadap objek tertentu, dan diharapkan akan terbentuk niat dalam melakukan objek tersebut.

Hal tersebut sesuai dengan apa yang dikemukakan oleh Heri Purwanto (1998) yang dikutip dari buku Wawan dan Dewi M (2011) tentang sifat sikap yang dibagi atas :

a. Sikap positif kecenderungan tindakan adalah mendekati, menyenangi, mengharapkan obyek tertentu.

b. Sikap negatif terdapat kecenderungan untuk menjauhi, menghindari, membenci, tidak menyukai obyek tertentu.

Adapun teori yang di kemukakan oleh Azwar S (2008) dalam Wawan A (2010), bahwa sikap memiliki 3 komponen yang saling mendukung yaitu : Komponen kognitif yang merupakan respresentasi apa yang dipercayai oleh individu pemilik sikap, komponen kognitif berupa kepercayaan stereotipe yang dimiliki individu mengenai sesuatu dapat disamakan penanganan (opini) terutama apabila menyangkut masalah isu atau problem yang kontroversial. Komponen afektif merupakan perasaan yang menyangkut aspek emosional. Dan Komponen konatif merupakan aspek kecenderungan berperilaku tertentu sesuai dengan sikap yang dimiliki oleh seseorang. 
Sikap adalah suatu reaksi atau respon seseorang yang masih tertutup dari seseorang terhadap suatu stimulus atau objek, sikap itu merupakan kesiapan atau ketersediaan untuk bertindak dan bukanmerupakan pelaksana motif tertentu.

Sikap adalah penilaian (bisa berupa pendapat) seseorang terhadap stimulus atau obyek (dalam hal ini adalah masalah kesehatan, termasuk penyakit).

Dari pengertian diatas dapat disimpulkan bahwa sikap adalah kesediaan atau respon seseorang terhadap suatu objek di suatu lingkungan tertentu. Sikap terdiri dari 4 tingkatan (Notoatmodjo, 2012) yaitu :

a. Menerima (receiving) artinya bahwa orang (subjek) dan memperhatikan stimulus yangdiberikan (objek).

b. Merespon (responding) artinya memberikan jawaban apabila ditanya, mengerjakan dan menyelesaikan tugas yang diberikan suatu indikasi dari sikap karena dengan suatu usaha untuk menjawab pertanyaan atau tugas yang diberikan.

c. Menghargai (valuing) artinya mengajak orang lain untuk mengerjakan atau mendiskusikan suatu masalah. d. Bertanggung jawab (responsible) artinya bertanggung jawab dengan segala sesuatu yang dipilihnya.

Hal lain yang menjadi factor penyebab sehingga responden tidak mampu menampakkan perilaku yang positif (melaksanakan PHBS) adalah Karena adanya keterbatasan secara fisik yang disebabkan Karena factor usia responden yang sudah mencapai 60 tahun dan tinggal dalam keluarga yang mayoritas penghuninya memiliki kesibukan dan aktifitas di luar rumah yang sangat padat, sehingga dengan kendala dan hambatan fisik tersebut sehingga responden tidak mampu untuk mewujudkan perilaku sesuai yang diharapkan.

\section{KESIMPULAN}

Berdasarkan hasil penelitian tersebut maka dapat disimpulkan sebagai berikut :

1. Ada hubungan pengetahuan dengan pelaksanaan PHBS di Wilayah Kerja Puskesmas Sombaopu Kabupaten Gowa ( $p$-value $=0,000<\alpha=0,05)$, yang artinya semakin baik pengetahuan yang dimiliki keluarga maka akan semakin baik pula pelaksanaan/penerapan PHBS di tatanan rumah tangga di Wilayah Kerja Puskesmas Sombaopu 
Kabupaten Gowa, dan sebaliknya semakin rendah pengetahuan keluarga maka akan semakin tidak melaksanakan / menerapkan PHBS di tatanan rumah tangga di Wilayah Kerja Puskesmas Sombaopu Kabupaten Gowa.

2. Ada hubungan sikap dengan pelaksanaan PHBS di Wilayah Kerja Puskesmas Sombaopu Kabupaten Gowa ( $p$-value $=0,000<\alpha=0,05$ ), yang artinya semakin baik sikap yang dimiliki keluarga maka akan semakin baik pula pelaksanaan/penerapan PHBS di tatanan rumah tangga di Wilayah Kerja Puskesmas Sombaopu Kabupaten Gowa, dan sebaliknya semakin kurang baik sikap keluarga maka akan semakin tidak melaksanakan / menerapkan PHBS di tatanan rumah tangga di Wilayah Kerja Puskesmas Sombaopu Kabupaten Gowa.

\section{SARAN}

Saran yang dapat peneliti berikan terkait dengan temuan hasil penelitian ini adalah :

1. Bagi Institusi, diharapkan lebih intensif dan terlibat aktif dalam kerjasama mengadakan penyuluhan berkala tentang pentingnya dan manfaat dari PHBS.
2. Bagi keluarga Penelitian ini diharapkan dapat memberikan informasi tentang manfaat PHBS bagi keluarga

\section{UCAPAN TERIMA KASIH}

Ucapan terima kasih penulis ucapkan terhadap semua pihak yang telah membantu pelaksanaan penelitian ini. 


\section{DAFTAR PUSTAKA}

(2011). Pedoman PHBS. [Online] Dari : http //dinkessulsel.go.id/new/images/pdf/pedoman/pedoman\%20 phbs.pdf. Diakses 13 September 2016

Arikunto, S, 2011. Prosedur Penelitian suatu Pendekatan praktik ed.IV. RinekaCipta: Jakarta

Azwar, Syaifuddin, 2008. Metode Penelitian, Yogyakarta : Pustaka Pelajar

Budiarto, Eko, 2002. Biostatistika Untuk Kedokteran dan Kesehatan Masyarakat, Jakarta : EGC

Dariyo, Agoes, 2004. Psikologi Perkembangan Remaja. Bogor Selatan : Galia Indonesia

Departemen Kesehatan Republik Indonesia, 2007. Rumah Tangga Sehat Dengan Perilaku Hidup Bersih Dan Sehat

Departemen Kesehatan RI.(2010). Keluarga sehat investasi bangsa. [Online].http://www.depkes.go.id/index.php/berita/press-release/1309-keluargasehat-investasi-bangsa.html. diakses pada 13 September 2016

Dinas Kesehatan RI, 2001. Buku Saku Pelaksanaan PHBS Bagi Masyarakat di Wilayah Kecamatan

Habibah. (2008). Hubungan Pengetahuan Sikap dan Penerapan Perilaku Hidup Bersih dan Sehat. Universitas Widyagama Mahakam. Samarinda. dari http://digilib.uns.ac.id. diakses pada tanggal 13 September 2016

Hidayat, Azis Alimul, 2007. Metode Penelitian Kebidanan, Teknis Analisis Data. Jakarta : Salemba Medika

Notoadmodjo, 2003. Pendidikan dan Perilaku Kesehatan. Jakarta : Rineka Cipta

Notoadmodjo, 2005. Metodologi Penelitian Kesehatan. Jakarta : Rineka Cipta

Notoadmodjo, 2007. Kesehatan Masyarakat, Ilmu dan Seni. Jakarta : Rineka Cipta

Notoadmodjo, 2007. Promosi Kesehatan dan Ilmu Perilaku. Jakarta : Rineka Cipta

Notoatmodjo, Soekidjo. 2011.Pendidikan dan Perilaku Kesehatan, Jakarta, PT. Asdi Mahasatya,

Nursalam, 2001. Konsep dan Metodologi Penelitian Ilmu Keperawatan. Jakarta : Salemba Medika

Nursalam, 2003. Konsep dan Metodologi Penelitian Ilmu Keperawatan. Jakarta : Salemba Medika

Nursalam, 2008. Konsep dan Metodologi Penelitian Ilmu Keperawatan. Jakarta : Salemba Medika

Perilaku Hidup Bersih dan Sehat. (2011). (Online), (http://www.perdhaki.org/content/perilaku-hidup-bersih-dan-sehat, diakses pada 06 September 2016)

Pradana, A. (2012). Perilaku Hidup Bersih dan Sehat. (Online), (http://info-kesehatankita.blogspot.com/2012/01/perilaku-hidup-bersih-dan-sehat-phbs.html ,diakses pada 06 September 2016) 
Promosi Kesehatan. (Online), (http://id.wikipedia.org/wiki/Promosi_kesehatan,diakses pada 06 September 2016)

Proverawati, A. (2012). Perilaku Hidup Bersih dan Sehat (PHBS). Yogyakarta: Nuha Medika

Pusat Promosi Kesehatan. (2012). Promosi Kesehatan Dalam Pencapaian Perilaku Hidup $\begin{array}{llll}\text { Bersih dan Sehat (PHBS). } & \end{array}$ (http://www.promosikesehatan.com/?act=program\&id=12, diakses pada 06 September 2016)

Rumini \& Sundari, 2004. Perkembangan Anak dan Remaja. Jakarta : Rineka Cipta Ruchdiat, dkk, 2005. Hidup Sehat dan Bahagia. Bandung : Ikhtiar Publishing

Setiadi, 2007. Konsep dan Penulisan Riset Keperawatan. Yogyakarta : Graha Ilmu Sugiyono (2015). Metode Penelitian Kuantitatif Kualitatif dan RD, Jakarta Penerbit Alfabeta,

Yusuf, Syamsu, 2009. Psikologi Perkembangan Anak dan Remaja. Bandung : PT Remaja Rosdakarya.

Wahyuni(2011).Gambaran Karakteristik Keluarga Tentang Perilaku Hidup Bersih dan Sehat (PHBS) pada Tatanan Rumah Tangga di Desa Karangasem Wilayah Kerja Puskesmas Tanon II Sragen. Jurnal GASTER, Vol. 8, No. 2

Wawan, A dan Dewi, M. 2011. Teori dan Pengukuran Pengetahuan, Sikap dan Perilaku Manusia. Cetakan ke-2. Yogyakarta, Penerbit Nuha Medika 